\title{
Acidic Mesoporous Zeolite ZSM-5 Supported Cu Catalyst with Good Catalytic Performance in the Hydroxysulfurization of Styrenes with Disulfides
}

\author{
Jun $\mathrm{Hu}^{1}{ }^{1}$, Chaojie Zhu ${ }^{2}$, Feifei Xia ${ }^{1}$, Zhongxue Fang ${ }^{2}$, Fengli Yang ${ }^{1}$, Jushi Weng ${ }^{1}$, Pengfei Yao ${ }^{1}$, \\ Chunzhi Zheng ${ }^{1}$, Hai Dong ${ }^{2}$ and Wenqian $\mathrm{Fu}^{2, *}$ \\ 1 School of Chemical and Environmental Engineering, Jiangsu University of Technology, Changzhou 213001, \\ China; jhu@jsut.edu.cn (J.H.); xff7461198@163.com (F.X.); 252391742@163.com (F.Y.); \\ wengjushi@jsut.edu.cn (J.W.); yaopengfei@jsut.edu.cn (P.Y.); zhengcz@jsut.edu.cn (C.Z.) \\ 2 School of Petrochemical Engineering, Changzhou University, Changzhou 213164, China; \\ zhcj1103@163.com (C.Z.); fangzhongxue@cczu.edu.cn (Z.F.); dh@wxtcxny.com (H.D.) \\ * Correspondence: fuwenqian@cczu.edu.cn; Tel.: +86-0519-8633-0009
}

Received: 20 November 2017; Accepted: 13 December 2017; Published: 19 December 2017

\begin{abstract}
Development of highly active heterogeneous catalysts is an effective strategy for modern organic synthesis chemistry. In this work, acidic mesoporous zeolite ZSM-5 (HZSM-5-M), acidic-free mesoporous zeolite TS-1 (TS-1-M), and basic ETS-10 zeolite supported metal Cu catalysts were prepared to investigate their catalytic performances in the hydroxysulfurization of styrenes with diaryl disulfides. The effect of pore size and acidities of the supports, as well as the $\mathrm{Cu}$ species electronic properties of the catalysts on reaction activity were investigated. The results show that $\mathrm{Cu}^{+}$and $\mathrm{Cu}^{2+}$ binded on HZSM-5-M show the highest activity and product selectivity for the desired $\beta$-hydroxysulfides compounds.
\end{abstract}

Keywords: mesoporous zeolite ZSM-5; copper; hydroxysulfurization; acidity

\section{Introduction}

$\beta$-Hydroxysulfides are important intermediates for synthesis of various valuable biological active compounds, pharmaceuticals, and natural products, such as renin and leukotrienes [1-3]. Traditional methods for the preparation of $\beta$-hydroxysulfides involve the ring opening of epoxides with sulfenyl that comes from thiols in the homogenous metal-catalyzed reaction systems [4-6]. However, this protocol usually suffers from relatively low activity and undesirable side reaction [1]. To improve the reaction activity and product selectivity, many strategies have been developed. For example, various functional organic ligands were added into reaction mixtures for modification of the metals' electronic property to improve the reaction activity $[7,8]$; irradiation or peroxides were used in the reaction systems for the generation of sulfenyl radicals, improving the product selectivity $[3,9,10]$. Nevertheless, the product separation from the reaction mixture is complicated and catalyst reuse is difficult. From a sustainable and practical point of view, developing a highly efficient heterogeneous catalyst is significant for preparation of $\beta$-hydroxysulfide compounds.

It is well known that crystalline aluminosilicate zeolites have high surface area, tunable acidity, and unique framework structure [11], which as supports or catalysts show superior catalytic performance in many organic syntheses, such as carbon-carbon coupling [12], Knoevenagel [13], and oxidative coupling reactions [14]. As a continuous work focus on development of highly efficient heterogeneous catalyst for synthetic chemistry, in this work, H-form mesoporous zeolite ZSM-5 (HZSM-5-M) supported $\mathrm{Cu}$ catalyst $(\mathrm{Cu} / \mathrm{HZSM}-5-\mathrm{M})$ was prepared and applied in the hydroxysulfurization of 
alkenes. The results show that $\mathrm{Cu} / \mathrm{HZSM}-5-\mathrm{M}$ exhibits high activity and good product selectivity, and shows no significant change in catalytic activity after seven repetitions.

\section{Experimental Section}

\subsection{Material Synthesis}

Water glass is a sodium silicate $\left(\mathrm{Na}_{2} \mathrm{O} \cdot 4 \mathrm{SiO}_{2}, \mathrm{SiO}_{2} 24.6\right.$ wt. \%, $\mathrm{Na}_{2} \mathrm{O} 6.8$ wt. \%) solution, which was purchased from Zhejiang Tongxiang Water Glass Factory (Tongxiang, China). The other chemicals, aluminum sulfate $\left(\mathrm{Al}_{2}\left(\mathrm{SO}_{4}\right)_{3} \cdot 18 \mathrm{H}_{2} \mathrm{O}, 99 \%\right)$ and tetrapropylammonium hydroxide (TPAOH, $25 \%$ ), were purchased from Sinopharm Chemical Reagent Co., Ltd. (Shanghai, China).

Mesoporous zeolite ZSM-5 (ZSM-5-M) was synthesized in the gel containing cationic copolymer (denoted as RCC) as mesoscale template, where RCC was synthesized from diallylamine and diallylammonium chloride [15]. As a typical run, $15.8 \mathrm{~mL}$ water glass, $20 \mathrm{~mL}$ water and $0.4 \mathrm{~mL}$ tetrapropylammonium hydroxide ( $25 \mathrm{wt} . \%, \mathrm{TPAOH})$, and $6 \mathrm{~mL}$ RCC was mixed in sequence and stirred for $2 \mathrm{~h}$. Next, $40 \mathrm{~mL}$ acidic aluminum sulfate solution $(0.05 \mathrm{~mol} / \mathrm{L})$ was added dropwise in to the mixture and stirred for $2 \mathrm{~h}$. The composition of this gel was $\mathrm{Al}_{2} \mathrm{O}_{3} / 45 \mathrm{SiO}_{2} / 12 \mathrm{Na}_{2} \mathrm{O} / 0.28 \mathrm{RCC} /$ $0.2 \mathrm{TPAOH} / 2049 \mathrm{H}_{2} \mathrm{O}$. After this gel hydrothermal treatment at $170{ }^{\circ} \mathrm{C}$ for $48 \mathrm{~h}$ in Teflon-coated stainless-steel autoclave, the sample was collected by filtrating, washing with water, drying at $100{ }^{\circ} \mathrm{C}$ for $12 \mathrm{~h}$, and calcination at $550{ }^{\circ} \mathrm{C}$ for $5 \mathrm{~h}$ in air. Micropore zeolite ZSM-5 was synthesized with same procedure in the absence of RCC. Mesoporous zeolite TS-1 (TS-1-M) and ETS-10 were prepared according to previous works $[13,16]$. ZSM-5-M and ZSM-5 samples were ion-exchanged with $\mathrm{NH}_{4} \mathrm{NO}_{3}$ $(1 \mathrm{M})$ solution for $4 \mathrm{~h}$ at $80^{\circ} \mathrm{C}$, and was collected by filtration, drying at $100^{\circ} \mathrm{C}$ for $12 \mathrm{~h}$, and calcination in air at $500^{\circ} \mathrm{C}$ for $4 \mathrm{~h}$ for transformation to H-form samples (HZSM-5-M and HZSM-5).

\subsection{Catalyst Preparation}

The catalyst with $\mathrm{Cu}$ metal loading of $3 \mathrm{wt}$. \% was prepared from incipient-wetness impregnation method. Typically, HZSM-5-M was impregnated with a solution containing an appropriate amount of $\mathrm{Cu}\left(\mathrm{NO}_{3}\right)_{2} \cdot 6 \mathrm{H}_{2} \mathrm{O}$, followed by drying at atmospheric temperature for $24 \mathrm{~h}$ and at $100{ }^{\circ} \mathrm{C}$ for $12 \mathrm{~h}$. Finally, the dried sample was calcined at $450{ }^{\circ} \mathrm{C}$ for $4 \mathrm{~h}$ in air, and the obtained catalyst sample was denoted as $\mathrm{Cu} / \mathrm{HZSM}-5-\mathrm{M}$. The $\mathrm{Cu} / \mathrm{HZSM}-5, \mathrm{Cu} / \mathrm{ETS}-10$, and $\mathrm{Cu} / \mathrm{TS}-1-\mathrm{M}$ catalysts were prepared using the same method. Additionally, Fe and Co supported on HZSM-5-M (Fe/HZSM-5-M and Co/HZSM-5-M) catalysts were also prepared by the same method except for using iron nitrate hydrate and cobalt nitrate hydrate, respectively.

\subsection{Characterization}

X-ray powder diffraction (XRD) pattern was obtained on a D/MAX 2500/PC powder diffractometer (Rigaku, Ltd., Tokyo, Japan) by using a $\mathrm{Cu} K \alpha$ radiation source. $\mathrm{N}_{2}$ adsorption-desorption isotherms were measured at $-196{ }^{\circ} \mathrm{C}$ on a Micromeritics ASAP2020M apparatus (Micromeritics Instrument Ltd., Darmstadt, Germany). The acidities of the supports were measured by ammonia temperatureprogrammed desorption $\left(\mathrm{NH}_{3}-\mathrm{TPD}\right)$ on a Micromeritics ASAP2920 instrument (Micromeritics Instrument Ltd., Darmstadt, Germany) according to previous work [15]. Total acidic site density of the support was determined by acid-base titration method [15]. The obtained $\mathrm{NH}_{3}-\mathrm{TPD}$ curve was deconvoluted at different maximum peak temperatures with a Gaussian function for fitting [17], and the peak areas were calculated. In this manner, the peak areas were correlated with the amount of adsorbed $\mathrm{NH}_{3}$ in different temperature regions. The morphology and mesoporous structure of ZSM-5-M were observed by field-emission scanning electron microscope (SEM, SUPRA55, Zeiss Gruppe, Heidenheim, Germany) and transmission electron microscope (TEM, JEM-2100, JEOL Ltd., Tokyo, Japan), respectively. The electronic state of the $\mathrm{Cu}$ species in catalysts was analyzed by X-ray photoelectron spectroscopy (XPS) on an ESCALAB MK II system (VG Scientific Ltd., East Grinstead, UK). $\mathrm{Cu}$ content and atomic $\mathrm{Si} / \mathrm{Al}(\mathrm{Ti})$ in the different samples were determined 
by inductively coupled plasma optical emission spectroscopy (ICP-OES) on a Perkin-Elmer 3300DV emission spectrometer (PerkinElmer, Waltham, MA, USA). The Cu content in Cu/ZSM-5-M, Cu/ZSM-5, $\mathrm{Cu} / \mathrm{TS}-1-\mathrm{M}$, and $\mathrm{Cu} / \mathrm{ETS}-10$ catalysts was 3.0, 2.9, 3.0, and $2.9 \mathrm{wt}$ \% , respectively (Table S1).

\section{Results and Discussion}

\subsection{Catalyst Characterization}

XRD patterns of ZSM-5-M and HZSM-5-M in Figure 1 a give diffraction peaks at $2 \theta=7.9^{\circ}, 8.9^{\circ}, 23^{\circ}$, $23.9^{\circ}$, and $24.5^{\circ}$, which is typical characteristics of ZSM-5 zeolite structure [15]. After loading of $\mathrm{Cu}$ on HZSM-5-M and calcination, the XRD diffraction peak position and intensity did not change, indicating that the ZSM-5 zeolite structure is well maintained for the Cu/HZSM-5-M sample. The diffraction peaks related with $\mathrm{Cu}$ species are not observed in the XRD pattern of $\mathrm{Cu} / \mathrm{HZSM}-5-\mathrm{M}$, suggesting that small metal particles are dispersed in the $\mathrm{Cu} / \mathrm{HZSM}-5-\mathrm{M}$ sample. Similar phenomena were also observed in XRD patterns of TS-1-M and basic ETS-10 supported Cu catalysts (Figure S1). Nitrogen adsorption-desorption isotherms of ZSM-5-M and Cu/HZSM-5-M samples give a steep step at relative pressure of $0.6-0.96$ (Figure $1 \mathrm{~b}$ ), which is related to the presence of mesopores in the samples. Their corresponding mesopore size mainly centered at 22 and $21 \mathrm{~nm}$ (Figure S2), respectively.

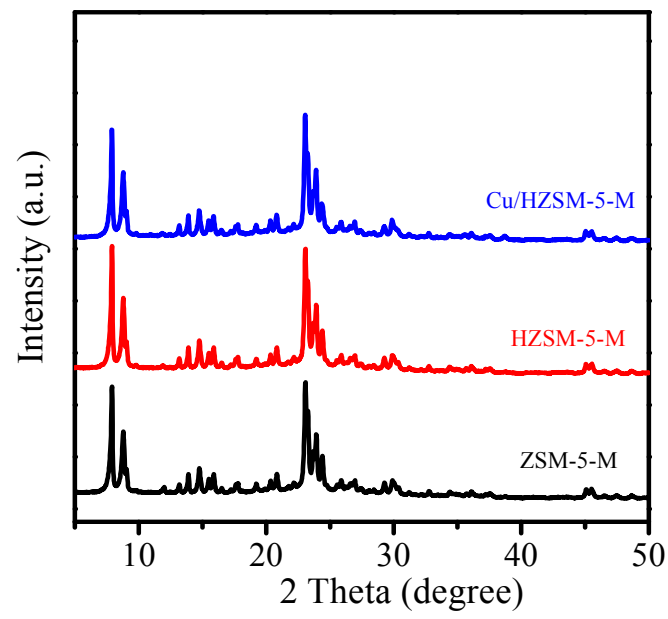

(a)

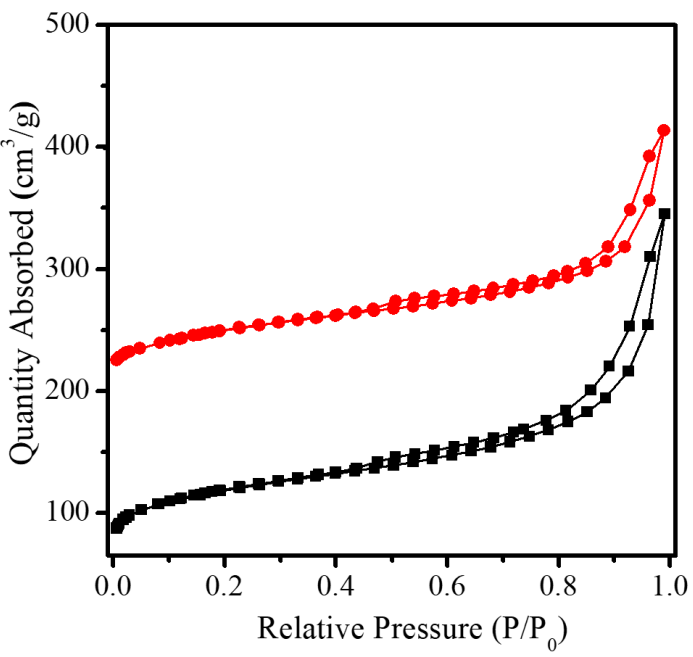

(b)

Figure 1. (a) XRD patterns of ZSM-5-M, HZSM-5-M and Cu/HZSM-5-M samples; (b) $\mathrm{N}_{2}$ adsorption isotherms of the $(\boldsymbol{\square})$ ZSM-5-M and $(\bullet)$ Cu/HZSM-5-M samples.

Figure 2a shows the SEM image of ZSM-5-M, giving a cylinder-like morphology with rough surface. The large cylinder-like particles are composed of nano-crystals with sizes of 50-150 nm. In this case, meso-macropores could be formed in the nanocrystal assemblies. The morphology of the TS-1-M, ZSM-5, and ETS-10 zeolites were also observed by SEM technique, and the results are shown in Figure S3. The SEM image reveals that the TS-1-M crystal particle exhibits a rough surface and has a particle size of 200-300 nm, while both of ZSM-5 and ETS-10 zeolite have a smooth surface with a large particle size.

The porous structure of the ZSM-5-M was characterized by TEM technique. It was observed that not only many intra-crystalline mesopores (white lines), but also abundant inter-crystalline mesopore and marcopores (light areas), are present in ZSM-5-M particles (Figure 2b).

The dispersion of metal partials on $\mathrm{Cu}$ /HZSM-5-M was observed by TEM technique, and the results are shown in Figure 3. The low-magnification TEM image shows that small metal particles (3-5 nm) highly disperse on the Cu/HZSM-5-M (Figure 3a). The high-magnification TEM image in Figure $3 \mathrm{~b}$ displays that some metal particles with a lattice fringe of 0.21 and $0.22 \mathrm{~nm}$ corresponds to 
the (111) crystal plane of $\mathrm{Cu}_{2} \mathrm{O}$ and (200) crystal plane of $\mathrm{CuO}$ [18], respectively. This result indicates that some copper could be present in the form of $\mathrm{Cu}_{2} \mathrm{O}$ and $\mathrm{CuO}$ on the $\mathrm{Cu} / \mathrm{HZSM}-5-\mathrm{M}$ sample.

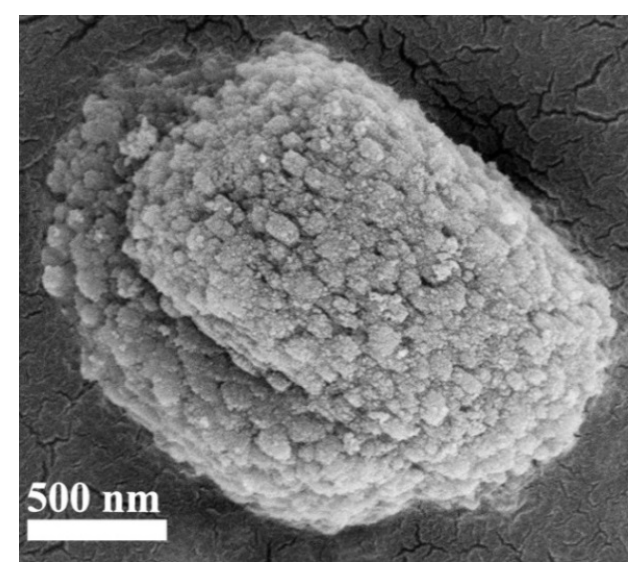

(a)

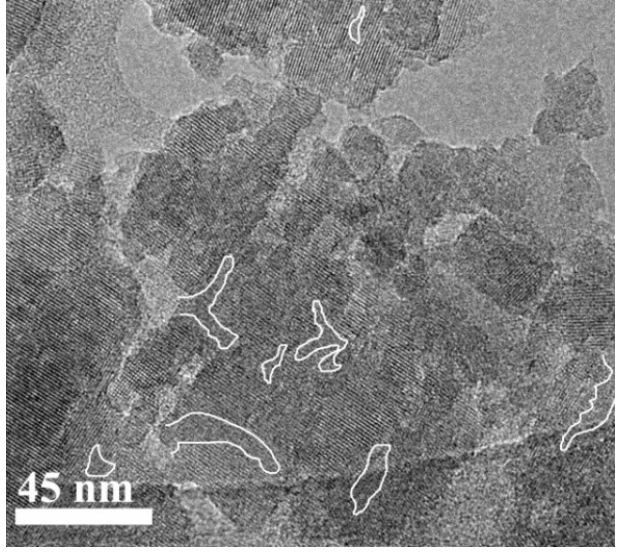

(b)

Figure 2. (a) Scanning electron microscope (SEM) and (b) transmission electron microscope (TEM) images of the ZSM-5-M sample.

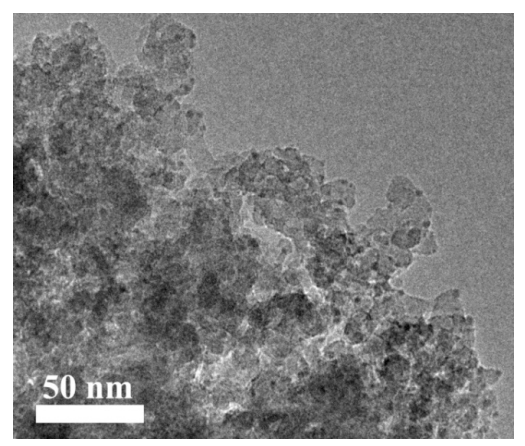

(a)

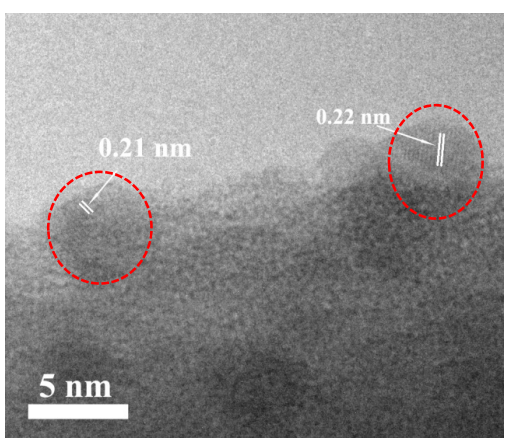

(b)

Figure 3. TEM images of the $\mathrm{Cu} / \mathrm{HZSM}-5-\mathrm{M}$ sample (a) in a low-magnification and (b) in a high high-magnification (The metal particles in Figure $3 b$ were surrounded by red circle).

Figure 4 shows the $\mathrm{NH}_{3}$-TPD curves of the HZSM-5 and HZSM-5-H, giving similar $\mathrm{NH}_{3}$ desorption profile with peaks around 224,326 , and $421^{\circ} \mathrm{C}$, indicating that weak, medium, and strong acid sites are present in these samples. However, HZSM- 5 has a large number of total acid site densities relative to HZSM-5-M. The acid-base titration results also demonstrated that the number of weak, medium and strong acid site on HZSM-5 is higher than that on HZSM-5-M (Table 1). The $\mathrm{NH}_{3}$ desorption signal of TS-1-M sample was inconspicuous, indicating the absence of acidity on TS-1-M sample.

Table 1. Total acidity and acidic site distribution of the HZSM-5-M and HZSM-5 samples ${ }^{1}$.

\begin{tabular}{|c|c|c|c|c|}
\hline Catalyst & $\begin{array}{l}\text { Weak Acid Site } \\
\quad\left(\mu \mathrm{mol} \cdot \mathrm{g}^{-1}\right)\end{array}$ & $\begin{array}{l}\text { Medium Acid Site } \\
\quad\left(\mu \mathrm{mol} \cdot \mathrm{g}^{-1}\right)\end{array}$ & $\begin{array}{l}\text { Strong Acid Site } \\
\quad\left(\mu \mathrm{mol} \cdot \mathrm{g}^{-1}\right)\end{array}$ & $\begin{array}{l}\text { Total Acid Site } \\
\left(\mu \mathrm{mol} \cdot \mathrm{g}^{-1}\right)\end{array}$ \\
\hline HZSM-5-M & 134 & 71 & 75 & 280 \\
\hline HZSM-5 & 282 & 110 & 106 & 498 \\
\hline
\end{tabular}

1 The weak, medium, and strong acid site is estimated from the corresponding area of the deconvoluted peaks, respectively, and the total acid site is determined by acid-base titration. 
The chemical state of the $\mathrm{Cu}$ species on $\mathrm{Cu} / \mathrm{HZSM}-5-\mathrm{M}$ and $\mathrm{Cu} / \mathrm{TS}-1-\mathrm{M}$ catalysts was investigated by XPS. The $\mathrm{Cu} 2 \mathrm{p}_{3 / 2}$ spectra in Figure 5 show two binding energies approximate 933.2 and $935.3 \mathrm{eV}$ on $\mathrm{Cu} / \mathrm{HZSM}-5-\mathrm{M}$ catalyst corresponding to the $\mathrm{Cu}^{+}$and $\mathrm{Cu}^{2+}$ species, respectively [19]. A similar phenomenon also existed on the $\mathrm{Cu} / \mathrm{TS}-1-\mathrm{M}$ catalyst. Meanwhile, the binding energies of the $\mathrm{Cu}^{+}$and $\mathrm{Cu}^{2+}$ species on the $\mathrm{Cu} / \mathrm{HZSM}-5-\mathrm{M}$ catalyst are lower than those on $\mathrm{Cu} / \mathrm{TS}-1-\mathrm{M}$ catalyst. This could be due to the fact that the metal-support interaction on the $\mathrm{Cu} / \mathrm{HZSM}-5-\mathrm{M}$ is stronger than Cu/TS-1-M. In addition, the content of the $\mathrm{Cu}^{+}$species is higher than $\mathrm{Cu}^{2+}$ species on both of $\mathrm{Cu} / \mathrm{HZSM}-5-\mathrm{M}$ and $\mathrm{Cu}$ /TS-1-M catalysts by XPS analysis (Table S2).

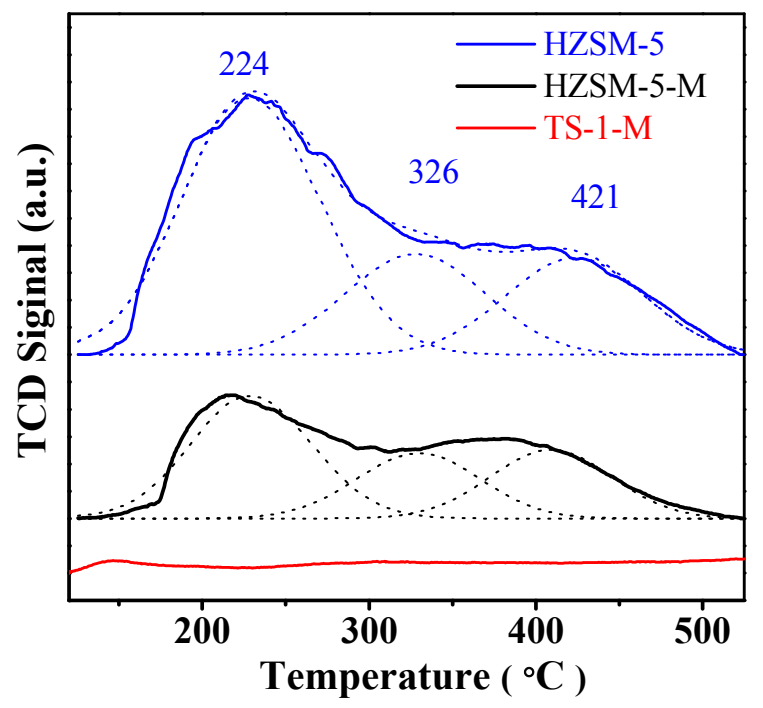

Figure 4. $\mathrm{NH}_{3}$-TPD curves and Gaussian deconvoluted peak of the samples.

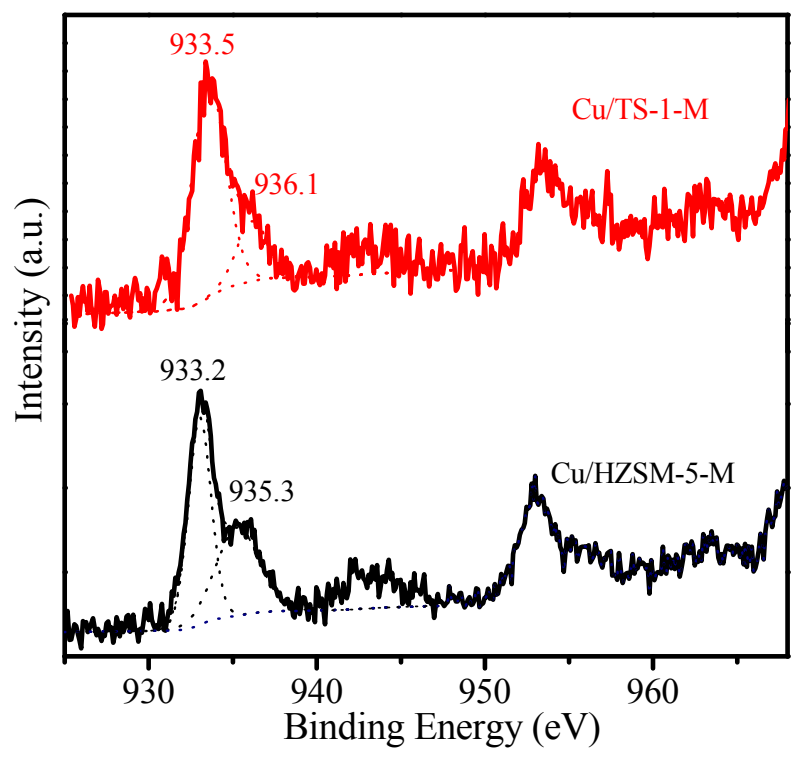

Figure 5. XPS spectra Cu2 $\mathrm{p}_{3 / 2}$ of the $\mathrm{Cu} / \mathrm{HZSM}-5-\mathrm{M}$ and $\mathrm{Cu} / \mathrm{TS}-1-\mathrm{M}$ samples.

\subsection{Catalytic Performance}

To optimize the reaction conditions, the hydroxysulfurization of styrene with diaryl disulfides was carried out with various oxidants and solvents under different temperatures (Table S3). Preliminary solvent screening experimental results show that dimethylsulfoxide (DMSO) $/ \mathrm{H}_{2} \mathrm{O}$ was the effective 
mixture solvent in the presence of iodine as oxidant at $80{ }^{\circ} \mathrm{C}$, affording styrene conversion of $89 \%$ and 1-phenyl-2-(phenylthio)ethanol product selectivity of 63\% (entries 1-6). After designation of DMSO $/ \mathrm{H}_{2} \mathrm{O}$ as solvent, the influence of oxidant on reaction activity was investigated. Compared to $t$-butylhydroperoxide (TBHP) and $\mathrm{H}_{2} \mathrm{O}_{2}$, iodine proved to be the most efficient oxidant (entries 7 and 8). When using $\mathrm{O}_{2}, \mathrm{~K}_{2} \mathrm{~S}_{2} \mathrm{O}_{8}$, and $\mathrm{KMnO}_{4}$ as oxidants, this reaction did not occur (entries 9-11). By optimization of the reaction temperature, it was found that the highest styrene conversion and the product selectivity at $80{ }^{\circ} \mathrm{C}$ were obtained (entries 12-15). Consequently, the reaction conditions were determined and followed as: styrene $(1.0 \mathrm{mmol})$, diaryl disulfides $(0.6 \mathrm{mmol}), 0.2 \mathrm{mmol}$ iodine, DMSO $/ \mathrm{H}_{2} \mathrm{O}(1: 1)$ as solvent, temperature of $80{ }^{\circ} \mathrm{C}$. The good reaction activity was obtained by using iodine as an oxidant, which could be due to fact that iodine can promote the formation of sulfonium ions from dibenzyl disulfide [20].

The catalytic performance of different catalysts was performed at the optimized reaction conditions, and the results are shown in Table 2. Initially, acidic HZSM-5-M shows the highest reaction activity and 1-phenyl-2-(phenylthio)ethanol selectivity, as compared to mesopore-free HZSM-5 and acid-free TS-1-M catalysts (entries 1-4). These results suggest that the catalyst with acidity favors this reaction. Compared with HZSM-5-M, the product selectivity is further improved on the $\mathrm{Cu} / \mathrm{HZSM}-5-\mathrm{M}$ catalyst (entries 2 and 5). The catalytic performance of the Cu/HZSM-5-M catalyst is also superior to that of Fe/HZSM-5-M and Co/HZSM-5-M catalysts (entries 5-7). Notably, although $\mathrm{Cu} / \mathrm{HZSM}-5$ catalyst gives similar styrene conversion to that $\mathrm{Cu} / \mathrm{HZSM}-5-\mathrm{M}$ catalyst, the product selectivity over $\mathrm{Cu} / \mathrm{HZSM}-5$ is lower than that over $\mathrm{Cu} / \mathrm{HZSM}-5-\mathrm{M}$ (entry 8). This could be due to the difference in porous structure between $\mathrm{Cu} / \mathrm{HZSM}-5$ and $\mathrm{Cu} / \mathrm{HZSM}-5-\mathrm{M}$ catalysts. Cu/HZSM-5-M has a high mesoporous surface area of $182 \mathrm{~m}^{2} / \mathrm{g}$ and mesoporous volume of $0.35 \mathrm{~cm}^{3} / \mathrm{g}$ (Table S1). In contrast, $\mathrm{Cu} / \mathrm{HZSM}-5$ has only a low external area of $27 \mathrm{~m}^{2} / \mathrm{g}$. The abundant mesopores in $\mathrm{Cu} / \mathrm{HZSM}-5-\mathrm{M}$ not only could be beneficial to the reactants accessible for active sites, but also favor the diffusion of the reactants, enhancing product selectivity. In addition, the acid-base property of the support strongly influences the reaction activity of their supported $\mathrm{Cu}$ catalysts. ETS-10 has strong basicity [13], and the Cu/ETS-10 catalyst only gives styrene conversion of 71\% (entry 9), even lower than the reaction system without catalyst, suggesting that the catalyst with basicity inhibits this reaction. Acidic-free TS-1-M supported Cu catalyst (Cu/TS-1-M) presents comparable activity to that $\mathrm{Cu}$ /HZSM-5-M, but 1-phenyl-2-(phenylthio)ethanol product selectivity of Cu/TS-1-M (76\%) is inferior to that of $\mathrm{Cu} / \mathrm{HZSM}-5-\mathrm{M}(84 \%$, entry 10$)$.

Table 2. Hydroxysulfurization reaction over different catalysts ${ }^{1}$.

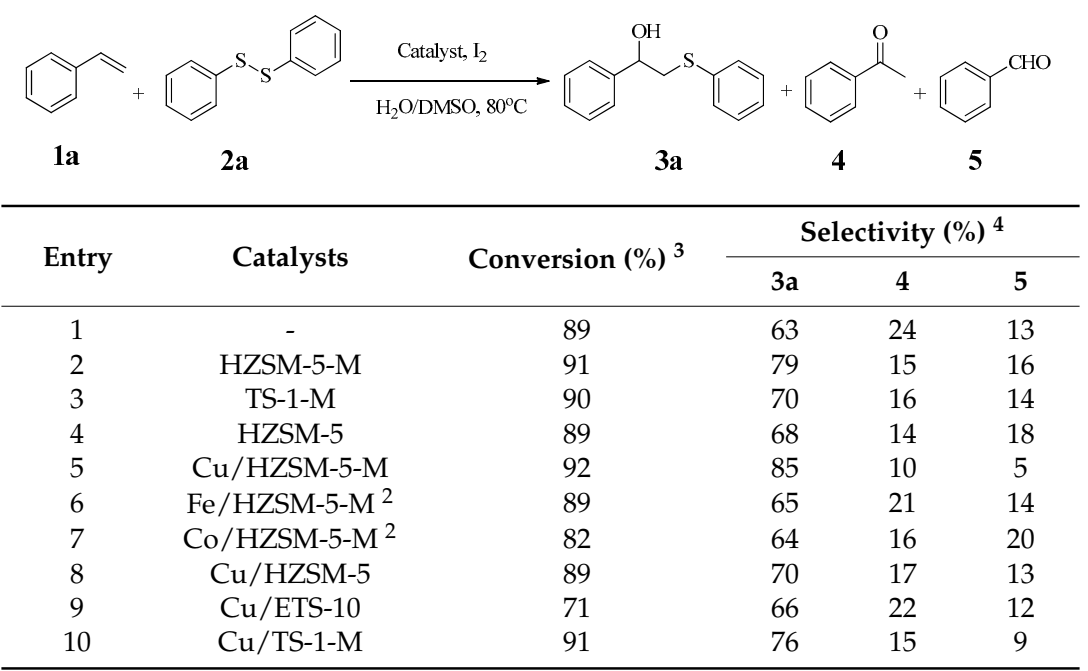

${ }^{1}$ Reaction condition: $25 \mathrm{mg}$ solid catalyst, alkenes $(1.0 \mathrm{mmol})$, diaryl disulfide $(0.6 \mathrm{mmol})$, oxidant $(0.2 \mathrm{mmol}), \mathrm{H}_{2} \mathrm{O}$ $(1 \mathrm{~mL}), \mathrm{DMSO}(1 \mathrm{~mL}), 80^{\circ} \mathrm{C}$ for $10 \mathrm{~h} .{ }^{2}$ The metal loading of Fe and Co. on Fe/HZSM-5-M and Co/HZSM-5-M catalysts is $3.0 \mathrm{wt}$ \%. ${ }^{3,4}$ The conversion and selectivity were analyzed by an Agilent 7890B GC (Agilent Technologies Inc., Santa Clara, CA, USA) equipped with a flame ionization detector. 
Based on our experiment result, it can be concluded that the $\mathrm{Cu}$ species and acidic sites on $\mathrm{Cu} / \mathrm{HZSM}-5-\mathrm{M}$ catalyst could enhance the catalytic performance. Our previous work demonstrated that acidic sites on zeolite can promote the adsorption of styrene through interaction of $\mathrm{C}=\mathrm{C}$ bond with the acidic sites, resulting in the activation of the $\mathrm{C}=\mathrm{C}$ bond, and the activated $\mathrm{C}=\mathrm{C}$ bond readily was attacked by electrophilic species to form the desired product [15]. In this work, compared with acid-free TS-1-M supported Cu catalyst, large amounts of acidic sites on $\mathrm{Cu}$ /HZSM-5-M catalyst could benefit the adsorption of styrenes, improving the reaction performance in the hydroxysulfurization reaction of styrenes. On the other hand, the $\mathrm{Cu}^{+}$and $\mathrm{Cu}^{2+}$ species in the catalyst could play an important role in this reaction. It has been reported that $\mathrm{Cu}$ salts acted on the disulfide as a Lewis acid or co-oxidant in air to give electrophilic sulfur species [8]. In our case, $\mathrm{Cu}^{+}$and $\mathrm{Cu}^{2+}$ species in the catalyst could also facilitate the formation of electrophilic sulfur species [8], which could attack the styrene to form the target product.

The reaction scope of this reaction over $\mathrm{Cu} / \mathrm{HZSM}-5-\mathrm{M}$ catalyst was also examined, and the results are given in Table 3. Cu/HZSM-5-M catalyst tolerates styrenes with electron-donating (methyl and $t$-butyl) and electron-withdrawing (fluorine, chlorine, and bromine) substituents, affording the desired products in good yields (3b-3i). The substrate of 2-naphthylethylene can also be employed in this transformation, giving a relatively low yield (3j). Furthermore, employing propenyl benzene as a substrate, it affords the desired product $3 \mathbf{k}$ in a gratifying yield. Additionally, diaryl disulfides containing nitro and bromine substituents were smoothly reacted with $p$-methylstyrene, and a moderate yield was obtained with the expected products (31 and $3 \mathrm{~m}$ ). Moreover, using cyclic aliphatic alkene and diaryl disulfides as substrates, the reaction still smoothly proceeded and desired product $\mathbf{3 n}$ in good yield. Notably, when the reagent of 4-pentenoic acid with internal nucleophile was employed as substrate, the target product of 2-((phenylthio)methyl)tetrahydrofuran $\mathbf{3 o}$ also was obtained. These results demonstrated that the $\mathrm{Cu} / \mathrm{HZSM}-5-\mathrm{M}$ catalyst presents good functional group compatibility in hydroxysulfurization reaction.

Table 3. Hydroxysulfurization reaction between alkenes and diaryl disulfides ${ }^{1}$.

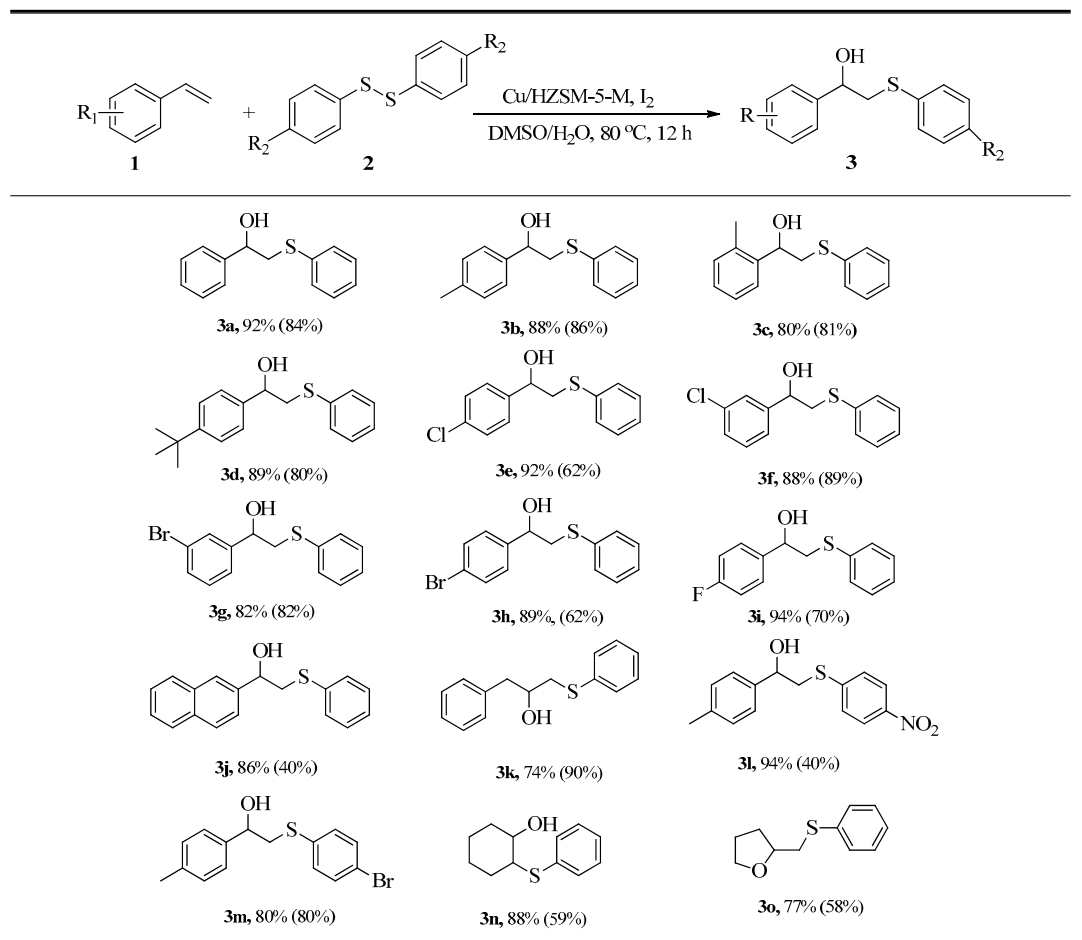

\footnotetext{
${ }^{1}$ Reaction condition: $25 \mathrm{mg}$ solid catalyst, alkenes $(1.0 \mathrm{mmol})$, diaryl disulfide $(0.6 \mathrm{mmol}), \mathrm{I}_{2}(0.2 \mathrm{mmol}), \mathrm{H}_{2} \mathrm{O}$ $(1.0 \mathrm{~mL}), \mathrm{DMSO}(1.0 \mathrm{~mL}), 80^{\circ} \mathrm{C}$ for $10 \mathrm{~h}$. The data out of parenthesis is conversion, and in parenthesis is selectivity, and the conversion and selectivity were analyzed by an Agilent 7890B GC equipped with a flame ionization detector.
} 
The reusable ability of Cu/HZSM-5-M catalyst was investigated (Table 4). Cu/HZSM-5-M catalyst exhibits relatively high activity and selectivity after it recycled seventh runs, nevertheless, the activity and product selectivity of $\mathrm{Cu} / \mathrm{HZSM}-5-\mathrm{M}$ were slightly reduced with an increase cycle times. This could be due to the fact that the leaching of $\mathrm{Cu}$ species in the Cu/HZSM-5-M catalyst occurred. When the $\mathrm{Cu} / \mathrm{HZSM}-5-\mathrm{M}$ was recycled seven times, the $\mathrm{Cu}$ content in the catalyst decreased from $3.0 \%$ for fresh one to $2.7 \mathrm{wt}$. \% (Table S1). The reused Cu/HZSM-5-M catalyst was also characterized by TEM, XRD, and $\mathrm{N}_{2}$-adsorption. TEM image shows that the metal particles are still present on the reused $\mathrm{Cu} / \mathrm{HZSM}-5-\mathrm{M}$ sample (Figure S4). The characteristic diffraction peaks in XRD pattern of the reused $\mathrm{Cu} / \mathrm{HZSM}-5-\mathrm{M}$ are the same as that of the fresh one (Figure S5). The reused $\mathrm{Cu} /$ HZSM-5-M catalyst has high BET surface area $\left(354 \mathrm{~m}^{2} / \mathrm{g}\right)$, external surface area $\left(175 \mathrm{~m}^{2} / \mathrm{g}\right)$, and mesoporous volume $\left(0.33 \mathrm{~cm}^{3} / \mathrm{g}\right.$, Table $\left.\mathrm{S} 1\right)$. These results suggest that $\mathrm{Cu} / \mathrm{HZSM}-5-\mathrm{M}$ exhibits good physico-chemical stability.

Table 4 . The reusability of the catalyst ${ }^{1}$.

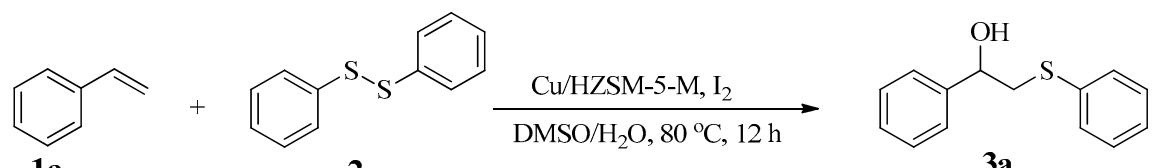

$1 \mathbf{a}$

2

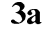

\begin{tabular}{cccc}
\hline Entry & Recycle & Conversion (\%) & Selectivity (\%) \\
\hline 1 & Run 1 & 92 & 84 \\
2 & Run 2 & 92 & 84 \\
3 & Run 3 & 91 & 83 \\
4 & Run 4 & 90 & 82 \\
5 & Run 5 & 89 & 82 \\
6 & Run 6 & 87 & 80 \\
7 & Run 7 & 88 & 80
\end{tabular}

${ }^{1}$ Reaction condition: $25 \mathrm{mg}$ solid catalyst, styrene $(1.0 \mathrm{mmol})$, diaryl disulfide $(0.6 \mathrm{mmol}), \mathrm{I}_{2}(0.2 \mathrm{mmol}), \mathrm{H}_{2} \mathrm{O}$ $(1.0 \mathrm{~mL}), \mathrm{DMSO}(1.0 \mathrm{~mL})$, reaction time of $10 \mathrm{~h}$. The yield was analyzed by GC. The spent catalyst was carefully collected, washed with acetonitrile 10 times, and dried at $120^{\circ} \mathrm{C}$ for $10 \mathrm{~h}$, and followed by calcination at $450{ }^{\circ} \mathrm{C}$ in air for the next recycle.

\section{Conclusions}

In conclusion, hierarchically porous zeolite ZSM-5 with cylinder-like morphology and micro-mesomacroporous structure was synthesized by using cationic copolymer as mesoscale template. After loading metal $\mathrm{Cu}$ on the H-form ZSM-5-M, the obtained Cu/HZSM-5-M presents good catalytic performance in the hydroxysulfurization of styrenes with diaryl disulfides, as compared to acidic micropore ZSM-5, acid-free TS-1-M, and basic ETS-10 supported Cu catalysts. This feature should be attributed to the fact that numerous acidic sites and $\mathrm{Cu}^{+}$and $\mathrm{Cu}^{2+}$ species in $\mathrm{Cu} / \mathrm{HZSM}-5-\mathrm{M}$ catalyst play a synergistic effect in improving the reaction activity and product selectivity. In addition, the prepared $\mathrm{Cu} / \mathrm{HZSM}-5-\mathrm{M}$ catalyst tolerates a variety of functional groups on both the styrenes and disulphide substrates, and has good reusability.

Supplementary Materials: The following are available online at http:/ /www.mdpi.com/2079-4991/7/12/459/s1, Figure S1: XRD patterns of (a) TS-1-M and Cu/TS-1-M and (b) ETS-10 and Cu/ETS-10 samples; Figure S2: The pore size distributions of the (ם) ZSM-5-M and (•) Cu/HZSM-5-M samples; Figure S3: SEM images of the (a) TS-1-M, (b) ZSM-5 and (c) ETS-10 zeolites; Figure S4: TEM image of reused Cu/HZSM-5-M catalyst; Figure S5: XRD patterns of fresh and reused $\mathrm{Cu}$ /HZSM-5-M catalysts; Table S1: Texture parameters of the different samples; Table S2: The results of deconvolution of XPS Cu2p3/2 peak of Cu/HZSM-5-M and Cu/TS-1-M samples; Table S3: Optimization of reaction conditions.

Acknowledgments: We gratefully acknowledge the financial supports from the National Natural Science Foundation of China (21476030 and U1662139), and the Natural Science Foundation of Jiangsu Province of China (BK20150258). 
Author Contributions: Wenqian Fu conceived and designed the experiments; Jun Hu and Chaojie Zhu performed the experiments; Jun Hu, Feifei Xia, and Zhongxue Fang analyzed the data; Fengli Yang, Jushi Weng, Pengfei Yao, Chunzhi Zheng, and Hai Dong contributed reagents/materials/analysis tools; Wenqian Fu wrote the paper.

Conflicts of Interest: The authors declare no conflict of interest.

\section{References}

1. Jay, R.L.; New, Y.; Jeff, S.; Herman, S.; Jerome, C.; Thomas, J.P.; Jacob, J.P. New inhibitors of human renin that contain novel Leu-Val replacements. J. Med. Chem. 1987, 30, 1609-1616.

2. Kamal, A.; Rajendar Reddy, D. Rajiendar. Direct one-pot synthesis of $\beta$-hydroxysulfides from terminal olefins in a mixture of $[\mathrm{bmim}]\left[\mathrm{BF}_{4}\right]$ and water in presence of molecular oxygen. J. Mol. Catal. A 2007, 272, 26-30. [CrossRef]

3. Pironti, V.; Colonna, S. Microwave-promoted synthesis of $\beta$-hydroxy sulfides and $\beta$-hydroxy sulfoxides in water. Green Chem. 2005, 7, 43-45. [CrossRef]

4. Iida, T.; Yamamoto, N.; Sasai, H.; Shibasaki, M. New asymmetric reactions using a Gallium complex: A highly enantioselective ring opening of epoxides with thiols catalyzed by a Gallium·Lithium·Bis(binaphthoxide) Complex. J. Am. Chem. Soc. 1997, 119, 4783-4784. [CrossRef]

5. Su, W.K.; Chen, J.X.; Wu, H.Y.; Jin, C. A general and efficient method for the selective synthesis of $\beta$-hydroxy sulfides and $\beta$-hydroxy sulfoxides catalyzed by gallium(III) triflate. J. Org. Chem. 2007, 72, 4524-4527. [CrossRef] [PubMed]

6. Azizi, N.; Saidi, M.R. $\mathrm{LiClO}_{4} \cdot 3 \mathrm{H}_{2} \mathrm{O}$ promoted highly regioselective ring-opening of epoxides with thiols under neutral conditions. Catal. Commun. 2006, 7, 224-227. [CrossRef]

7. Dowsland, J.; McKerlie, F.; Procter, D.J. Convenient preparation of ytterbium(III) chalcogenolate complexes by insertion of ytterbium into chalcogen-chalcogen bonds. Application in the ring-opening of epoxides. Tetrahedron Lett. 2000, 41, 4923-4927. [CrossRef]

8. Taniguchi, N. Copper-catalyzed 1,2-hydroxysulfenylation of alkene using disulfide via cleavage of the S-S bond. J. Org. Chem. 2006, 71, 7874-7876. [CrossRef] [PubMed]

9. Surendra, K.; Krishnaveni, N.S.; Sridhar, R.; Rao, K.R. Synthesis of $\beta$-hydroxysulfides from Alkenes under Supramolecular Catalysis in the Presence of $\beta$-Cyclodextrin in Water. J. Org. Chem. 2006, 71, 5819-5821. [CrossRef] [PubMed]

10. Zhou, S.F.; Pan, X.Q.; Zhou, Z.H.; Shoberu, A.; Zou, J.P. Air oxidative radical hydroxysulfurization of styrenes leading to $\beta$-hydroxysulfides. J. Org. Chem. 2015, 80, 3682-3687. [CrossRef] [PubMed]

11. Li, J.Y.; Corma, A.; Yu, J.H. Synthesis of new zeolite structures. Chem. Soc. Rev. 2015, 44, 7112-7127. [CrossRef] [PubMed]

12. Fu, W.Q.; Feng, Y.; Fang, Z.X.; Chen, Q.; Yu, Q.Y.; Tang, T.D. Zeolite Y nanosheet assembled palladium catalysts with high catalytic activity and selectivity in the vinylation of thiophenes. Chem. Commun. 2016, 52, 3115-3118. [CrossRef] [PubMed]

13. Ni, X.J.; Xiang, M.; Fu, W.Q.; Ma, Y.L.; Zhu, P.Y.; Wang, W.C.; He, M.Y.; Yang, K.Q.; Xiong, J.; Tang, T.D. Direct synthesis of mesoporous zeolite ETS-10 and Ni-ETS-10 with good catalytic performance in the knoevenagel reaction. J. Porous Mater. 2016, 23, 423-429. [CrossRef]

14. Chen, S.C.; Shao, Z.; Fang, Z.X.; Chen, Q.; Tang, T.; Fu, W.Q.; Zhang, L.; Tang, T.D. Design and synthesis of the basic $\mathrm{Cu}$-doped zeolite $\mathrm{X}$ catalyst with high activity in oxidative coupling reactions. J. Catal. 2016, 338, 38-46. [CrossRef]

15. Dong, H.; Zhang, L.; Fang, Z.X.; Fu, W.Q.; Tang, T.; Feng, Y.; Tang, T.D. Acidic hierarchical zeolite ZSM-5 supported Ru catalyst with high activity and selectivity in the seleno-functionalization of alkenes. RSC Adv. 2017, 7, 22008-22016. [CrossRef]

16. Kang, Z.Z.; Fang, G.Y.; Ke, Q.P.; Hu, J.B.; Tang, T.D. Superior catalytic performance of mesoporous zeolite TS-1 for the oxidation of bulky organic sulfides. Chem CatChem 2013, 5, 2191-2194. [CrossRef]

17. Wang, Y.D.; Tao, Z.C.; Wu, B.S.; Xu, J.; Huo, C.F.; Li, K.; Chen, H.M.; Yang, Y.; Li, Y.W. Effect of metal precursors on the performance of Pt/ZSM-22 catalysts for $n$-hexadecane hydroisomerization. J. Catal. 2015, 322, 1-13. [CrossRef] 
18. Wang, Z.L.; Liu, Y.X.; Martin, D.J.; Wang, W.B.; Tang, J.W.; Huang, W.X. $\mathrm{CuO}_{x}-\mathrm{TiO}_{2}$ junction: What is the active component for photocatalytic $\mathrm{H}_{2}$ production. Phys. Chem. Chem. Phys. 2013, 15, 14956-14960. [CrossRef] [PubMed]

19. Bin, F.; Wei, X.L.; Li, B.; Hui, K.S. Self-sustained combustion of carbon monoxide promoted by the $\mathrm{Cu}-\mathrm{Ce} / \mathrm{ZSM}-5$ catalyst in CO/O$/ \mathrm{O}_{2}$ atmosphere. Appl. Catal. B 2015, 162, 282-288. [CrossRef]

20. Tehri, P.; Aegurula, B.; Peddinti, R.K. Iodine-catalysed regioselective synthesis of $\beta$-hydroxysulfides. Tetrahedron Lett. 2017, 58, 2062-2065. [CrossRef]

2017 by the authors. Licensee MDPI, Basel, Switzerland. This article is an open access article distributed under the terms and conditions of the Creative Commons Attribution (CC BY) license (http://creativecommons.org/licenses/by/4.0/). 